$S T$ elevation $\left(V_{3} R<V_{4} R \leq V_{5} R\right)$ or even $S T$ elevation $\left(V_{3} R=V_{4} R=V_{5} R\right)$.

Continuous variables were analyzed using unpaired $t$ tests and categorical data were analyzed using Fisher's exact test. Data are presented as mean \pm standard deviation. $A$ value of $p<0.05$ was considered significant.

In group $B, S T$ elevation in the right chest leads was observed more frequently in the patients with proximal left anterior descending coronary artery disease (11 of $12,90 \%)$ than in patients with distal disease (1 of 11 , $9 \%)(p<0.001)$. When the incidence and degree of $S T$ elevation in the right chest leads were compared with group $A$ (Table I), group B patients, particularly the subset with proximal left anterior descending coronary artery disease, often showed accompanying ST elevation in the right chest leads $V_{3} R$ and $V_{4} R$ (not different from group $A$ ), but rarely in $V_{5} R$ (significantly different from group A). As for the pattern of $S T$ elevation in the right chest leads (Table II), rightward ST elevation was specific for group $A$.

This study indicates that, in anterior wall LV infarction-particularly when due to left anterior descending narrowing proximal to the first septal branch--the incidence of ST elevation was frequent in the medial right chest $V_{3} R$ and $V_{4} R$ leads, thus showing no difference from acute $R V$ infarction or inferior wall $L V$ infarction due to proximal right coronary artery disease, whereas it was decreased in the lateral right chest $\mathrm{V}_{5} \mathrm{R}$ lead. The only different pattern of ST elevation in the right chest leads betwecn the 2 conditions was rightward ST clevation, which was specific for acute RV infarction or acute inferior wall LV infarction due to proximal right coronary artery disease.

In anterior wall LV infarction, the intimate relation between ST elevation in the right chest leads and proximal left anterior descending coronary artery disease strongly suggests that the injury current from the septum would produce right chest lead ST elevation. Of course, it could be argued that the injury current from the concomitant anterior wall RV infarction produces the ST elevation in the right chest lead in such a situation. Although this possibility cannot be ruled out entirely, the following observations in anterior wall LV infarction make this unlikely; pathologic studies have indicated that RV involvement is absent ${ }^{6}$ or limited to only a small degree, ${ }^{7}$ and, even if present, the amount of RV involvement is not different between proximal and distal left anterior descending coronary artery disease ${ }^{7}$; also, a recent clinical study using radionuclide angiography has shown an extremely low incidence of RV involvement. ${ }^{8}$ However, the lack of precise septal wall motion analysis in our present study did not allow us to obtain direct proof that septal involvement contributed to this phenomenon. The role of the septum in the genesis of ST shift in the right chest leads should therefore be further clarified.

To date, the usefulness of the right chest leads for evaluation of anterior wall LV acute myocardial infarction has not yet been established. As was disclosed in this study, ST-segment elevation in the right chest $\mathrm{V}_{3} \mathrm{R}$ lead has a very high sensitivity $(92 \%)$ and specificity $(91 \%)$ for involvement of the first septal branch under this condition. Hence, a 12-lead electrocardiogram with right chest leads should be a routine part of the initial evaluation of anterior wall LV acute myocardial infarction to determine the location of the narrowing in the left anterior descending coronary artery and thus to estimate the extent of infarction.

1. Klein HO, Tordjman I, Ninio R, Sareli P, Oren V, Lang K, Geten J, Pauzne C, di Segni E, David D, Kaplinsky E. The early recognition of right ventricular infarction: diagnostic accuracy of the clectrocardiographic $\mathrm{V}_{4} \mathrm{R}$ lead. Circulation 1983;67:558-565.

2. Braat SH, Brugada P, den Dulk K, van Ommen V, Wcllens HJJ. Value of lead $\mathrm{V}_{4} \mathrm{R}$ for recognition of the infarct coronary artery in acute inferior myocardial infarction. Am I Cardiol 1984;53:1538-1541.

3. Robalino BD, Whitlow PL, Underwood DA, Salcedo EE. Electrocardiographic manifestations of right ventricular infarction. Am Heart $J$ 1989;118:138-144.

4. Charlap S, Schulhoff N, Mylavarapu S, Greengart A, Gelbfish J, Budzilowicz L, Hollander G, Lichstein E, Shani J. Effects of occlusion of the left anterior descending coronary artery during angioplasty on right-sided cardiac pressures and electrocardiographic changes. Am J Cardiol 1989;64:577-580.

5. Lorell B, Leinbach RC, Pohost GM, Gold HK, Dinsmore RE, Hutter AM Jr, Pastore JO, Desanctis RW. Right ventricular infarction: clinical diagnosis and differentiation from cardiac tamponade and pericardial constriction. Am J Cardiol 1979;13:465 471 .

6. Isner JM, Roberts WC. Right ventricular infarction complicating left ventricular infarction secondary to coronary heart disease. Am J Cardiol 1978;42:885 894.

7. Andersen HR, Falk E, Nielsen D. Right ventricular infarction: frequency, size and topography in coronary heart disease: a prospective study comprising 107 consecutive autopsies from a coronary care unit. $J$ Am Coll Cardiol 1987;10:1223-1232.

3. Feit F, Sherman W, Rey MJ, Stecy PJ, Nachamie MS, Cole WJ, Thornton JC, Rentrop KP. Right ventricular involvement in acute myocardial infarction: a report from the Second ML. Sinai-NYU reperfusion trial (abstr). I Am Coll Cardiol 1990;15:218A.

\title{
Emergency Stenting for Refractory Acute Coronary Artery Occlusion During Coronary Angioplasty.
}

Pim J. de Feyter, MD, Ivan DeScheerder, MD, Marcel van den Brand, MD, GertJan Laarman, MD, Harry Suryapranata, MD, and Patrick W. Serruys, MD

A cute coronary artery occlusion occurs in 2 to $11 \%$ of the patients who undergo coronary angioplasty and

From the Catheterization Laboratory, Thoraxcenter, University IIospital Rotterdam, P.O. Box 1738, 3000 DR Rotterdam, The Netherlands. Manuscript received April 17, 1990; revised manuscript received and accepted June 15, 1990. is the major cause of in-hospital mortality and morbidity associated with coronary angioplasty. ${ }^{1-4}$

This procedural complication is usually caused by an occlusive dissection in association with thrombosis, spasm and elastic recoil. If immediate redilatation is unsuccessful, emergency surgery is traditionally recommended, but because of the clinical instability of these ischemic pa- 
TABLE I Baseline Clinical Characteristics of Patients with Emergency Stent Implantation

\begin{tabular}{|c|c|c|c|c|c|c|}
\hline Pt & $\begin{array}{l}\text { Age (yrs) } \\
\& \text { Sex }\end{array}$ & Symptoms & Vessels & LVEF & $\begin{array}{l}\text { PTCA } \\
\text { Artery }\end{array}$ & Medication Refore PTCA \\
\hline 1 & $41 \mathrm{M}$ & UÁP (post Mi) & 2 & 62 & LAD & $\mathrm{rtPA} / \mathrm{H} / \mathrm{NTG} / \mathrm{CA} / \mathrm{BB}$ \\
\hline 2 & $54 \mathrm{M}$ & UAP & 1 & 63 & LAD & $\mathrm{H} / \mathrm{NTG} / \mathrm{BB} / \mathrm{Asp} / \mathrm{CA}$ \\
\hline 3 & $70 \mathrm{M}$ & AP & 3 & 55 & Right & $\mathrm{BB} / \mathrm{CA} / \mathrm{Asp}$ \\
\hline 4 & $74 \mathrm{M}$ & UAP (post MI) & 1 & 62 & LAD & $\mathrm{rtPA} / \mathrm{NTG} / \mathrm{BB} / \mathrm{CA} / \mathrm{H}$ \\
\hline 5 & $64 \mathrm{M}$ & AP & 1 & 65 & LAD & $\mathrm{BB} / \mathrm{CA} / \mathrm{NTG}$ \\
\hline 6 & $58 \mathrm{~F}$ & UAP & 1 & 56 & Right $(100 \%)$ & $\mathrm{H} / \mathrm{NTG} / \mathrm{BB} / \mathrm{CA}$ \\
\hline 7 & $68 \mathrm{M}$ & UAP & 1 & 74 & LAD & $\mathrm{H} / \mathrm{BB} / \mathrm{CA} / \mathrm{NTG}$ \\
\hline 8 & $45 \mathrm{M}$ & UAP & 2 & 65 & LAD & $\mathrm{H} / \mathrm{NTG} / \mathrm{BB}$ \\
\hline 9 & $76 \mathrm{~F}$ & AP & 3 & 50 & Right & $\mathrm{CA} / \mathrm{NTG}$ \\
\hline 10 & $42 \mathrm{~F}$ & UAP & 1 & 50 & LAD & $\mathrm{CA} / \mathrm{NTG} / \mathrm{BB}$ \\
\hline 11 & $63 \mathrm{M}$ & UAP & 1 & 72 & $\operatorname{LCX}$ & $\mathrm{BB} / \mathrm{Asp} / \mathrm{CA} / \mathrm{NTG}$ \\
\hline 12 & $62 \mathrm{M}$ & UAP & 1 & 60 & Right & $\mathrm{BB} / \mathrm{NTG}$ \\
\hline 13 & $64 \mathrm{M}$ & UAP & 2 & 88 & LAD & $\mathrm{CA} / \mathrm{BB} / \mathrm{NTG}$ \\
\hline 14 & $56 \mathrm{M}$ & $\mathrm{AP}$ & 1 & NA & Right & $\mathrm{BB} / \mathrm{Asp}$ \\
\hline 15 & $69 \mathrm{~F}$ & AP & 1 & 59 & LAD & $\mathrm{BB} / \mathrm{CA} / \mathrm{NTG} / \mathrm{H}$ \\
\hline
\end{tabular}

TABLE II Technical and Clinical Data Pertinent for Emergency Stent Implantation

\begin{tabular}{|c|c|c|c|c|c|c|}
\hline Pt & $\begin{array}{l}\text { Time of Initial } \\
\text { Occlusion to } \\
\text { Stent Implantation } \\
\text { (min) }\end{array}$ & $\begin{array}{l}\text { Additional } \\
\text { Medication }\end{array}$ & $\begin{array}{l}\text { No. of Stents } \\
\text { Implanted }\end{array}$ & $\begin{array}{l}\text { Diameter (mm) } \\
\text { Unconstrained }\end{array}$ & $\begin{array}{l}\text { Length (mm) } \\
\text { Unconstrained }\end{array}$ & $\begin{array}{l}\text { Maximal Creatine } \\
\text { Phosphokinase } \\
(\mathrm{U} / \mathrm{ml})\end{array}$ \\
\hline 1 & 45 & UK & 1 & 4.0 & 14 & 149 \\
\hline 2 & 65 & STK I UK & 1 & 3.5 & 24 & 228 \\
\hline 3 & 55 & UK & 1 & 3.0 & 24 & 50 \\
\hline 4 & 60 & $r \mathrm{rPA}+\mathrm{UK}$ & 2 & 3.0 & 18 & 79 \\
\hline 5 & 65 & UK & 1 & 4.0 & 28 & 307 (non-Q-wave) \\
\hline 6 & 45 & UK & 1 & 4.0 & 25 & 103 \\
\hline 7 & 50 & UK & 1 & 3.5 & 18 & 250 \\
\hline 8 & 75 & UK & 1 & 4.0 & 14 & 273 \\
\hline 9 & 10 & UK & 1 & 3.5 & 19 & 41 \\
\hline 10 & 60 & UK & 1 & 3.5 & 22 & 105 \\
\hline 11 & 10 & UK & 1 & 4.0 & 19 & 24 \\
\hline 12 & 360 & UK & 2 & 4.0 & 20 & 548 (Q wave) \\
\hline 13 & 250 & UK & 2 & 3.5 & 22 & 439 (Q wave) \\
\hline 14 & 15 & UK & 2 & 4.5 & 22 & 81 \\
\hline 15 & 70 & UK & 1 & 3.5 & 22 & 589 (non-Q-wave) \\
\hline
\end{tabular}

lients, acute surgery is associated with high perioperative mortality and morbidity, and despite emergent revascularization, development of myocardial infarction cannot be prevented in a substantial number of patients. ${ }^{5}$ New methods that can restore anterograde flow and effectively stabilize the clinical condition after refractory acute occlusion are highly desirable. They may serve as a safe bridge until subsequent surgery or may even serve as an alternative to surgery. Emergency stent implantation in the dissected segment has been shown to restore anterograde flow. ${ }^{6,7}$ However, because the first generation of stents had a high tendency to acute thrombotic occlusion, it was decided that emergency stent implantation should be followed by "semi-elective" surgery. This study reports the acute results of the management of acute coronary artery occlusion refractory to redilation with emergency stent implantation followed by "semi-elective" bypass surgery in most of these patients.

From April 1989 through January 1990, emergency stenting for acute coronary artery occlusion was performed in 15 patients. The study protocol was approved by the hospital ethics committee. Acute coronary artery occlusion was defined as clinical or electrocardiographic evidence of myocardial ischemia and a critical reduction in blood flow in the vessel dilated. Patients were selected for emergency stent implantation if they fulfilled the following criteria: $(1)$ occurrence of symptomatic acute coronary artery occlusion during or after coronary angioplasty; (2) repeat balloon angioplasty (same balloon or larger size balloon or longstanding inflations with Stack balloon) was unsuccessful; (3) coronary vasculature considered suitable for stenting: vessel size $\geq 3 \mathrm{~mm}$ in diameter, no important difference in diameter of segments to be stented, no extreme tortuosity of vessels; (4) predominant cause of acute coronary artery occlusion suspected to be a combination of dissection, intraintimal hemorrhage, or vessel wall recoil, or both, and not intracoronary thrombosis; (5) location of the refractory occlusion so that the stent would not be implanted into the left main stem; (6) large area of myocardium at risk for subsequent necrosis; and (7) potential candidate for emergency bypass surgery. Criteria for patients not con- 
sidered suitable candidates for stenting were (1) contraindication for intensive short-term anticoagulation, or (2) presence of acute myocardial infarction.

Coronary angioplasty was performed according to current standard clinical practice. In most of the patients, a monorail balloon catheter was used. All patients received aspirin $(250 \mathrm{mg})$ before the procedure and they underwent full heparinization (10.000 U bolus with repeat doses of $5.000 \mathrm{U}$ every hour during long-lasting procedures). Refractory acute coronary artery occlusion was defined as failure of intracoronary administration of nitroglycerin, repeat dilatation or addition of thrombolytic treatment to successfully reopen the occluded segment.

The stent (Wall-stent/Medinvent ${ }^{(}$) consists of a stainless steel alloy with a self-expanding mesh design. The stent is flexible along its long axis, its length varies between 15 and $28 \mathrm{~mm}$ in an unconstrained situation, and its diameter in the fully expanded state varies between 3.0 and $4.0 \mathrm{~mm}$. The stent is maintained in a constrained and elongated position on a delivery system by a doubled-over membrane. This delivery system is introduced into the coronary artery through a standard $8 \mathrm{Fr}$ or $9 \mathrm{Fr}$ guiding catheter over a long guide wire ( 300 $\mathrm{cm}, 0.014$ to $0.018 \mathrm{inch}$ ). Retraction of the membrane. progressively releases the stent, first distally into the vascular lumen. For any given segment, a stent is selected which in its fully expanded state is somewhat "oversized." After stent implantation all patients received up to 250,000 U of intracoronary urokinase (during 10 to 30 minutes). Heparin was continued until the next day, when it was discontinued for 3 hours to allow the sheaths to be removed after which it was continued until semielective surgery. The patients were monitored in the coronary care unit. The patients who were not scheduled for subsequent surgery continued to receive heparin infusion (in doses sufficient to achieve a prolongation 2 times normal of the activated partial thromboplastin time) until the anticoagulant treatment with coumadin was considered adequate $(<10 \%$ thrombo test time). In addition, they were also treated with a combination of aspirin $(500 \mathrm{mg} /$ day $)$ and persantin $(3 \times 75 \mathrm{mg} /$ day $)$.

During a study period of 8 months, 505 consecutive, percutaneous transluminal coronary angioplasties were performed (patients referred for acute myocardial infarction were excluded), and refractory acute coronary artery occlusion occurred in 36 patients. Five patients were treated conservatively because the area of myocardium at risk was small (3 patients), the patient was not accepted for surgery (1 patient) or surgical standby was not available ( 1 patient). The acute occlusion was presumably caused by thrombosis in 6 patients, and they were treated with thrombolytic agents. Ten patients were referred for acute surgery; retrospectively, they all would have been suitable candidates for emergency stent implantation, but this was not performed because either the stent or an experienced team was not available. Fifteen patients underwent emergency stent implantation.

The baseline clinical characteristics, the pertinent stent implantation data and the detailed in-hospital course and management after implantation are listed in Tables I and II. Implantation was technically successful in all cases, without significant procedural complications. Subsequently, 8 patients underwent semielective bypass surgery ( 1 to 2 days after implantation) and none developed $Q$-wave myocardial infarction. In 2 other patients, surgery was scheduled, but 1 patient died because of intracranial bleed (within 12 hours after stent implantation) and the other patient had an acute occlusion of the stent within 12 hours after implantation; this was successfully reopened and followed by emergency surgery. In 5 patients, operation was not considered necessary. Ilowever, I patient had an acute thrombotic occlusion within the stent 7 days after implantation resulting in $Q$-wave infarction, and another patient had an acute occlusion of the stent within 24 hours resulting in extension of a recent infarction. The clinical course was uneventful in the 3 remaining patients.

Acute coronary artery occlusion during percutaneous transluminal coronary angioplasty is the major cause of in-hospital mortality and morbidity. ${ }^{1-4}$ An effective bailout technique would make coronary angioplasty safer and would significantly expand the pool of patients who could then be safely approached with coronary angioplasty.

Acute coronary artery occlusion at the site of dilatation is usually the result of a combination of dissection, spasm and thrombosis. ${ }^{1-4}$ Differentiation of these possibilities with angiography is often difficult, if not impossible, but should be considered to manage this complication more optimally. The optimal treatment of acute occlusion would first consist of immediate restoration of adequate anterograde coronary flow and second, institution of measures to ensure maintenance of flow. Intracoronary administration of nitroglycerin and redilatation with the same balloon, an "oversized" balloon, or long-lasting inflations while maintaining anterograde flow with a perfusion balloon is the recommended and accepted first line of treatment. If redilation is unsuccessful, acute bypass surgery is usually required. However, emergency bypass surgery after angioplasty complicated by acute coronary artery occlusion is associated with an increased mortality and morbidity when compared with elective procedures. ${ }^{5}$

This emphasizes the need for an easily applicable, reliable technique capable of restoring anterograde flow after unsuccessful angioplasty complicated by acute coronary artery occlusion. Such a technique should be able to restore the ischemic condition during an interval period, so that definitive surgery can be undertaken on a "semielective" basis in patients with a stable clinical condition, which should decrease operative morbidity and mortality.

We confirm the results of other studies: Stenting is technically feasible, it restores anterograde blood flow, it may prevent myocardial infarction and it is associated with an acceptable incidence of complications. ${ }^{6,7}$ Placement of a stent is indicated in selected patients if refractory acute coronary artery occlusion is associated with a dissection, intimal hemorrhage or elastic recoil either occurring alone or in combination. However, if intraluminal thrombosis appears to be the predominant mechanism, implantation of a stent could potentially aggravate the pathologic process and until now should be regarded a contraindication. Retrospective analysis of 36 patients with refractory acute coronary artery occlusion disclosed 
that 25 patients $(69 \%)$ were potentially suitable candidates for acute stent implantation.

Stent implantation is associated with potential problems. First, stents are potentially thrombogenetic and have shown a high tendency for acute thrombosis. ${ }^{8}$ This requires meticulous anticoagulation, which may induce serious bleeding complications, even fatal cerebral hemorrhage, as has occurred in 1 of our patients. In fact, despite intense anticoagulation, acute thrombosis within the stent occurred in 3 of 15 patients, resulting in a myocardial infarction in 2 and acute surgery in another. Because acute thrombosis within the current generation of stents is still a significant problem, we believe that it is prudent to refer these patients for bypass surgery. Second, intracoronary stent implantation may induce coronary spasm; however, this is reversible with use of intracoronary nitroglycerin, and to date has not resulted in myocardial necrosis. Third, the stent may act as a trigger for accelerated neointimal hyperplasia leading to restenosis. Last, in the setting of acute coronary artery occlusion and emergency stenting, some additional problems in placing the stent may arise: (1) Correct stent positioning is laborious because of the lack of visible sidebranches that act as landmarks, due to the absence of adequate anterograde flow. (2) Patients with acute coronary artery occlusion are often clinically unstable, with long-lasting periods of ischemia, hemodynamic deterioration and extensive dissection which may have induced activation of platelets and the clotting system, all of which may more easily lead to acute thrombosis of the stent. (3) The choice of the size of the stent may be difficult because acute coronary artery occlusion is often associated with spasm of reference vessel segment.

1. Dorros G, Cowley MJ, Simpson J, Bentivoglio LG, Block PC, Bourassa M, Detre K, Gosselin AJ, Grüntrig AR, Kelsey SF, Kent KM, Mock MB, Mullin S.M. Myler RK, Passamani L:R, Stertzer SH, Williams DO. Percutaneous transluminal coronary angioplasty: report of complications from the National Heart, Lung, and Blood Institute PTCA Registry. Circulation 1983;67:723-730.

2. Simpfendorfer C, Bclardi J, Bellamy G, Galan K, Franco I, Hollman J. Frequency, management, and follow-up of paticnts with acute coronary occlusions after percutaneous transluminal coronary angioplasty. AM J Cardiol 1987;59: 267-269.

3. Ellis SG, Ruubin GS, King III SB, Douglas JS Jr, Weintraub WS, Thomas RG, Cox WR. Angiographic and clinical predictors of acute closurc after native vessel coronary angioplasty. Circulation 1988;77:372-379.

4. FIllis SG, Roubin GS, King III SB, Douglas IS Jr, Shaw RE. Stertzer SH Myler RK. In-hospital cardiac mortality after acule clasure after coronary angioplasty: analysis of risk factors from 8.207 procedures. $J \mathrm{Am}$ Coll Cardiol 1988;11:211 -216.

5. Talley JD, Jones F.L, Weintraub WS, Kinger SB. Coronary artery bypass surgery after failed elective percutancous transiuminal coronary angioplasty. Circulation 1989;79(suppl I):I-126-I-131.

6. Sigwart U, Urban P, Golf S, Kaufnann U, Imbert $C$, Fischer $\Lambda$, Kappenberger L. Emergency stenting for acute $\propto$ celusion after coronary balloon angioplasty. Circulation 1988;78:1121-1127.

7. Roubin GS, Douglas JS, lembo NJ, Black AJ, King SB. Intracoronary stenting for acute closure following percutancous transluminal coronary angioplasty (abstr). Circulation 1988;77(suppl Il):II-407.

8. Scrruys PW, Beatt KJ, van der Giessen WJ. Stenting of coronary arteries: are we the sorcerer's apprentice? Eur Heart $J$ 1989;10:774-782. 